Review began 11/07/2021 Review ended 11/07/2021 Published 11/10/2021

๑) Copyright 2021

Penukonda et al. This is an open access article distributed under the terms of the Creative Commons Attribution License CCBY 4.0., which permits unrestricted use, distribution, and reproduction in any medium, provided the original author and source are credited.

\section{Sporadic Noradrenergic Adrenal Pheochromocytoma in an Adolescent Patient}

\author{
Sasi K. Penukonda ${ }^{1}$, Craig B. Chu ${ }^{2}$ \\ System, Shreveport, USA \\ Corresponding author: Sasi K. Penukonda, psasikiran@yahoo.com
}

1. Pediatric Endocrinology, Willis-Knighton Health System, Shreveport, USA 2. Pediatrics, Willis-Knighton Health

\begin{abstract}
Pheochromocytoma and paraganglioma are neuroendocrine tumors that occur less commonly among children compared to adults. The excess catecholamines secreted by the tumor cells result in hypertension, tachycardia, excess sweating, and headache. Other symptoms include abdominal pain or distension caused by the adrenal mass. Here, we report a case of pheochromocytoma arising from the left adrenal medulla in a 14-year-old boy, which was exclusively secreting norepinephrine, as suggested by elevated plasma and 24hour urinary norepinephrine and its metabolite normetanephrine. The epinephrine and its metabolite metanephrine were within normal limits. He presented with abdominal pain, recurrent vomiting, and headache and was noted to have elevated blood pressure. He underwent adrenalectomy after controlling his blood pressure with an alpha-blocker Prazosin. His blood pressure remained stable after surgery, and his plasma-free metanephrines returned to normal limits. He tested negative for hereditary paragangliomapheochromocytoma gene panel.
\end{abstract}

Categories: Endocrinology/Diabetes/Metabolism, Pediatrics, Pediatric Surgery

Keywords: adrenal, metanephrines, catecholamines, paraganglioma, pheochromocytoma

\section{Introduction}

Pheochromocytoma and paraganglioma are rare neuroendocrine tumors arising from the catecholamineproducing chromaffin cells of the adrenal medulla or paraganglia with an estimated incidence of 0.11 per million children [1]. Hypertension is the most consistent manifestation of these tumors, and it is more likely seen in children with or without paroxysmal crisis superimposed [2]. The excess catecholamines produced are mostly metabolized to metanephrines within the tumor cells by membrane-bound catecholamine Omethyltransferase [3]. Hence, the Endocrine Society guidelines recommend the measurement of plasma-free metanephrines or urinary fractionated metanephrines to diagnose pheochromocytoma and paraganglioma [4]. The catecholamine phenotype varies in pheochromocytoma and paraganglioma, with most paragangliomas presenting with lower epinephrine and metanephrine plasma concentrations compared to pheochromocytoma [5]. Here, we report a case of pheochromocytoma in a 14-year-old adolescent male patient with excess norepinephrine and normetanephrine but normal epinephrine and metanephrine levels.

\section{Case Presentation}

A 14-year-old adolescent male patient presented with incidentally discovered left adrenal mass measuring 6 $\times 6 \times 7.4 \mathrm{~cm}$ on a computed tomography (CT) scan (Figure 1 ) while being investigated for vague left upper abdominal pain and recurrent vomiting. On further questioning, he reported frequent headaches. There was no history of palpitations or excess sweating. His blood pressure was elevated around 140/78 $\mathrm{mmHg}$, and his heart rate was 103 beats per minute. 


\section{Cureus}

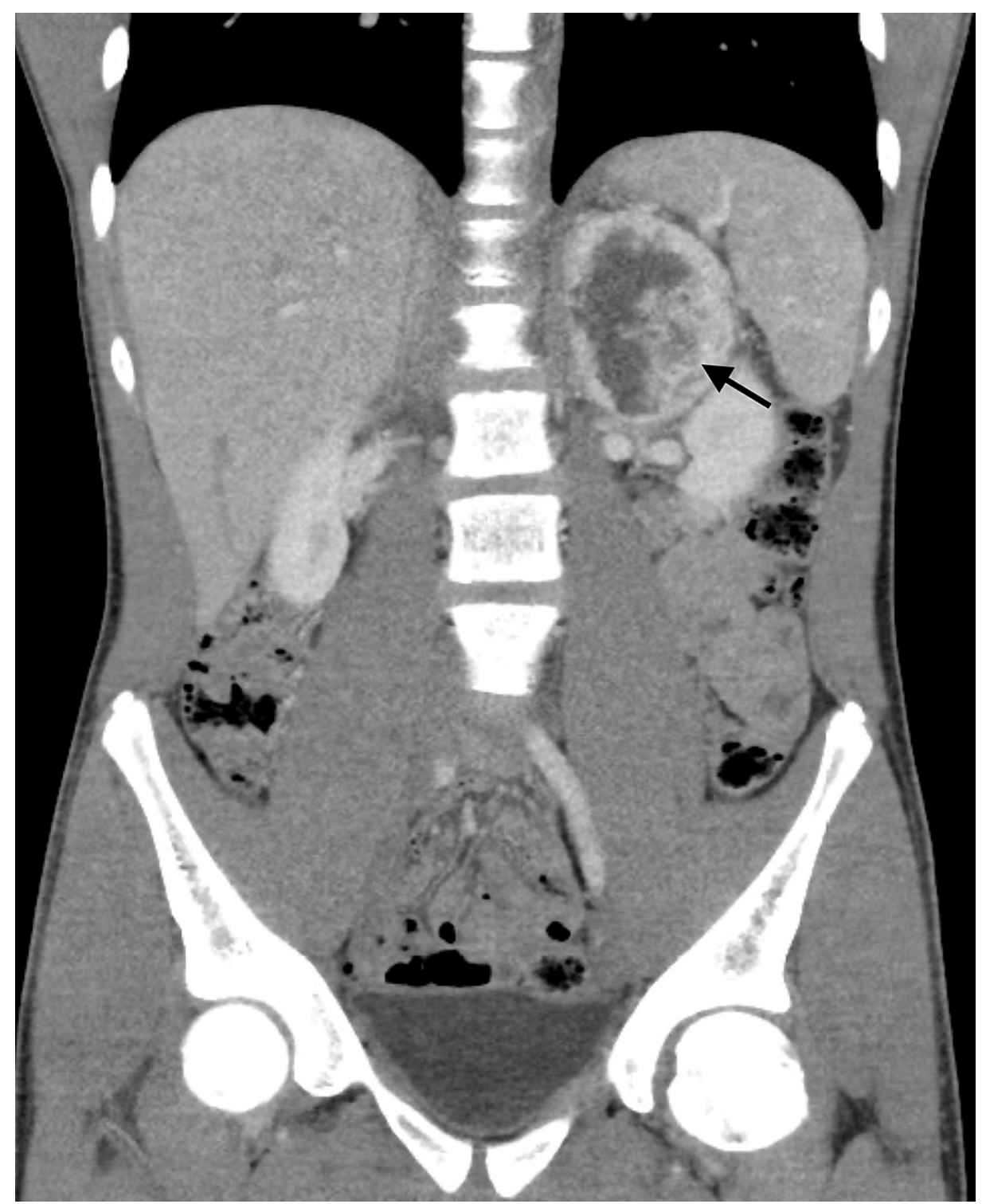

FIGURE 1: Coronal MPR CT image with contrast demonstrating heterogeneously enhancing left adrenal mass (black arrow).

MPR: multiplanar reformation; CT: computed tomography

Further investigations revealed elevated plasma-free normetanephrine and 24-hour urine normetanephrine and norepinephrine. Plasma-free metanephrine and 24-hour urine metanephrine and epinephrine were within normal limits (Table 1). 


\section{Cureus}

\begin{tabular}{|c|c|c|c|c|c|}
\hline \multicolumn{2}{|c|}{ Plasma-free metanephrines } & \multicolumn{2}{|c|}{$\begin{array}{l}\text { 24-hour urinary fractionated } \\
\text { metanephrines }\end{array}$} & \multicolumn{2}{|c|}{$\begin{array}{l}\text { 24-hour urinary fractionated } \\
\text { catecholamines }\end{array}$} \\
\hline $\begin{array}{l}\text { Free } \\
\text { normetanephrine }\end{array}$ & $\begin{array}{l}\text { Free } \\
\text { metanephrine }\end{array}$ & Normetanephrıne & Metanephrıne & Norepınephrıne & Epinephrine \\
\hline $30 \mathrm{nmol} / \mathrm{L}$ & $<0.2 \mathrm{nmol} / \mathrm{L}$ & $8,887 \mu g / 24$ hour & $92 \mu \mathrm{g} / 24$ hour & $574 \mu \mathrm{g} / 24$ hour & $1.9 \mu \mathrm{g} / 24$ hour \\
\hline \multicolumn{6}{|l|}{ Reference range } \\
\hline$<0.9 \mathrm{nmol} / \mathrm{L}$ & $<0.5 \mathrm{nmol} / \mathrm{L}$ & $91-456 \mu g / 24$ hour & 69-221 $\mu \mathrm{g} / 24$ hour & 15-80 $\mu \mathrm{g} / 24$ hour & $0.5-20 \mu \mathrm{g} / 24$ hour \\
\hline
\end{tabular}

TABLE 1: Laboratory findings at initial presentation.

Iodine-123 meta-iodobenzylguanidine scan revealed intense uptake in the region of mass in the left adrenal gland. No other abnormal areas of uptake were noted throughout the chest, abdomen, pelvis, extremities, head, and neck (Figure 2).

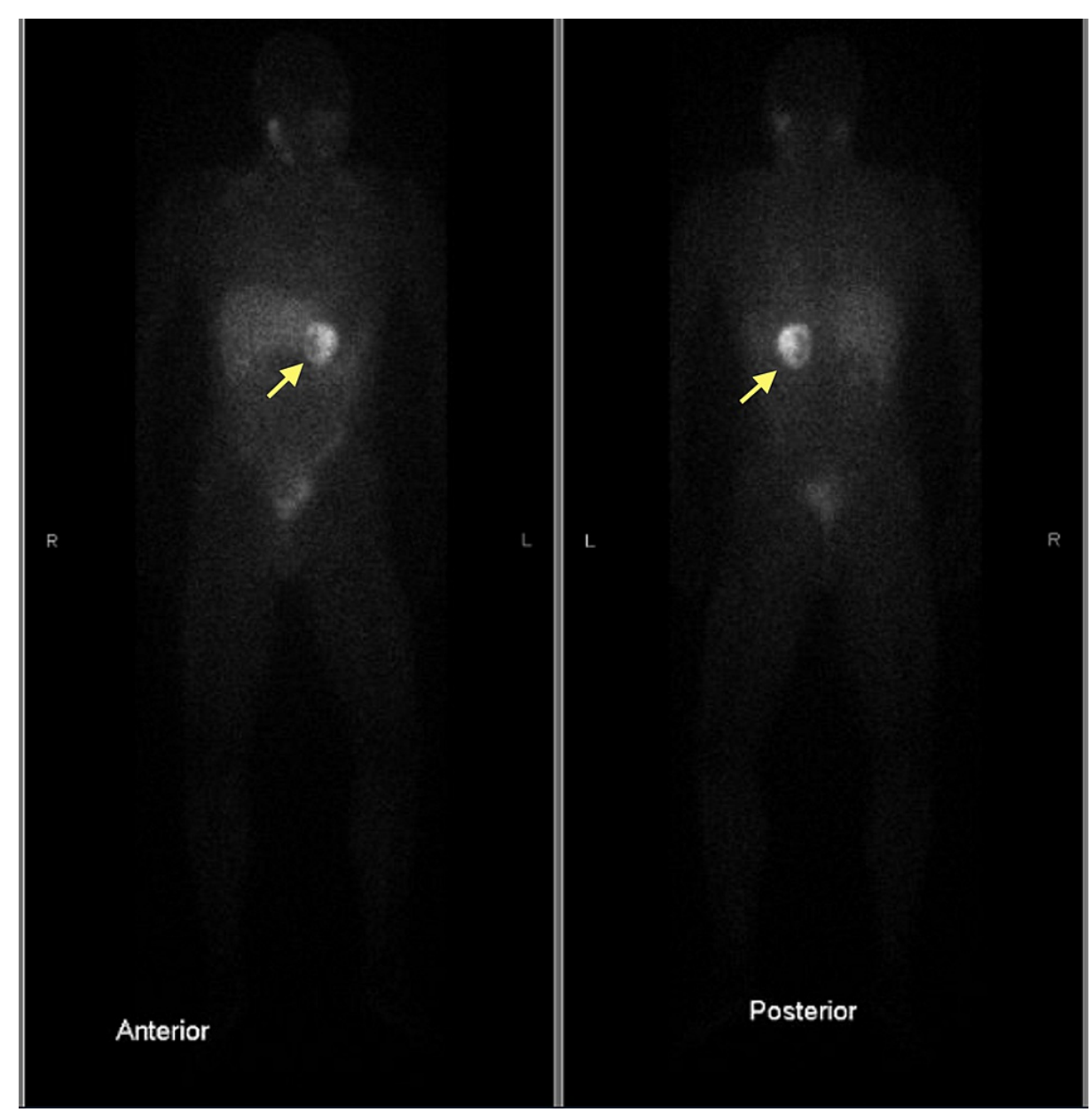

FIGURE 2: MIBG scan images showing intense uptake of iodine-123 in the region of the left adrenal mass (yellow arrow).

MIBG: meta-iodobenzylguanidine

He was treated with an alpha-blocker prazosin for two weeks prior to adrenalectomy to control his blood pressure. He was also advised a high-salt diet and increased fluid intake to expand blood volume and prevent hypotension after removal of the tumor. The patient underwent robot-assisted left adrenalectomy, and his postoperative period was uneventful. Prazosin was discontinued as his blood pressure remained stable after surgery. Biopsy confirmed the diagnosis of pheochromocytoma. His plasma-free metanephrine 


\section{Cureus}

levels two weeks after surgery were normal (Table 2).

\begin{tabular}{|c|c|c|c|}
\hline Plasma-tree metanephrınes & Betore surgery & I wo weeks atter surgery & Reference range \\
\hline Free normetanephrine & $30 \mathrm{nmol} / \mathrm{L}$ & $0.59 \mathrm{nmol} / \mathrm{L}$ & $<0.9 \mathrm{nmol} / \mathrm{L}$ \\
\hline Free metanephrine & $<0.2 \mathrm{nmol} / \mathrm{L}$ & $<0.2 \mathrm{nmol} / \mathrm{L}$ & $<0.5 \mathrm{nmol} / \mathrm{L}$ \\
\hline
\end{tabular}

TABLE 2: Plasma-free metanephrine levels before and after surgery.

He tested negative for hereditary paraganglioma-pheochromocytoma gene panel, including Von HippelLindau (VHL), succinate dehydrogenase complex subunit B (SDHB), succinate dehydrogenase complex subunit D (SDHD), and RET genes.

\section{Discussion}

Pheochromocytomas and paragangliomas are heterogenous tumors with diverse phenotypes. Paragangliomas predominantly or exclusively secrete norepinephrine, whereas epinephrine secretion is usually confined to pheochromocytomas arising from the adrenal medulla [6]. The excess production of epinephrine limited to tumors arising from the adrenal medulla is thought to be due to the proximity of these tumors to adrenal cortical steroids, which induce the production of phenylethanolamine- $\mathrm{N}$ methyltransferase (PNMT), the enzyme that converts norepinephrine to epinephrine [7]. However, it was later demonstrated that neither in vivo (direct contact between pheochromocytes and cortical cells) nor in vitro (pheochromocytes treated with dexamethasone) is sufficient to ensure PNMT transcription [5].

Approximately one-half of adrenal tumors produce nearly exclusively norepinephrine, and the other half produce a variable mixture of epinephrine and norepinephrine $[8,9]$. Our patient had adrenal pheochromocytoma exclusively producing norepinephrine. One study revealed that noradrenergic tumors usually present with sustained hypertension, as seen in our patient, and the tumors producing high levels of epinephrine cause paroxysmal hypertension [10]. More than $50 \%$ of patients aged less than 20 who present with pheochromocytoma/paraganglioma were found to have identifiable germline mutations, and the most common genes involved were VHL, RET, SDHD, and $S D H B$ [11]. The catecholamine phenotype in hereditary pheochromocytomas can vary with underlying gene mutation, with those from Von Hippel-Lindau syndrome (VHL gene mutation) producing predominantly norepinephrine, and the tumors from multiple endocrine neoplasia type 2 (RET gene mutation) producing a mixture of epinephrine and norepinephrine [12]. Our patient tested negative for all common genetic mutations associated with pheochromocytoma, suggesting sporadic type.

Surgical excision is the treatment of choice. Hormonally functional pheochromocytomas need treatment with alpha-blockers such as phenoxybenzamine or prazosin to prevent perioperative cardiovascular complications. Another option is the administration of calcium channel blockers. Beta-blockers can be added to control tachycardia after administration of alpha-blockers. Other supportive care includes a highsodium diet and increased fluid intake to reverse catecholamine-induced blood volume contraction preoperatively, and thereby prevent severe hypotension after tumor removal $[4,13]$.

Recent advances in laparoscopic surgery have increased the feasibility of laparoscopic adrenalectomy in pheochromocytoma [14,15]. Open surgery is recommended for tumors greater than $6 \mathrm{~cm}$ as it allows complete removal of the tumor and minimizes systemic catecholamine release [4]. Adrenal "cortical sparing" procedures have been advocated for patients with bilateral tumors to avoid the need for long-term steroid replacement and the risk of Addisonian crisis [15]. Our patient underwent robot-assisted adrenalectomy with one of the abdominal incisions widened to remove the intact adrenal mass.

\section{Conclusions}

Pheochromocytoma and paraganglioma are relatively rare in the pediatric population. Children presenting with adrenal mass or hypertension should be investigated for pheochromocytoma. Measurement of catecholamine metabolites such as normetanephrine and metanephrine in plasma and 24-hour urine helps accurately diagnose these tumors. Children diagnosed with pheochromocytoma/paraganglioma need further evaluation to rule out germline mutations associated with these tumors.

\section{Additional Information}

Disclosures

Human subjects: Consent was obtained or waived by all participants in this study. Conflicts of interest: In compliance with the ICMJE uniform disclosure form, all authors declare the following: Payment/services 
info: All authors have declared that no financial support was received from any organization for the submitted work. Financial relationships: All authors have declared that they have no financial relationships at present or within the previous three years with any organizations that might have an interest in the submitted work. Other relationships: All authors have declared that there are no other relationships or activities that could appear to have influenced the submitted work.

\section{References}

1. Spoudeas H, Harrison B: Paediatric endocrine tumours. A multidisciplinary consensus statement of best practice from a working group convened under the auspices of the BSPED and UKCCSG. Novo Nordisk Ltd., Sussex, UK; 2005.

2. Barontini M, Levin G, Sanso G: Characteristics of pheochromocytoma in a 4- to 20-year-old population . Ann N Y Acad Sci. 2006, 1073:30-7. 10.1196/annals.1353.003

3. Eisenhofer G, Keiser H, Friberg P, et al.: Plasma metanephrines are markers of pheochromocytoma produced by catechol-O-methyltransferase within tumors. J Clin Endocrinol Metab. 1998, 83:2175-85. 10.1210/jcem.83.6.4870

4. Lenders JW, Duh QY, Eisenhofer G, et al.: Pheochromocytoma and paraganglioma: an Endocrine Society clinical practice guideline. J Clin Endocrinol Metab. 2014, 99:1915-42. 10.1210/jc.2014-1498

5. Grouzmann E, Tschopp O, Triponez F, et al.: Catecholamine metabolism in paraganglioma and pheochromocytoma: similar tumors in different sites?. PLoS One. 2015, 10:e0125426. 10.1371/journal.pone.0125426

6. van der Harst E, de Herder WW, de Krijger RR, et al.: The value of plasma markers for the clinical behaviour of phaeochromocytomas. Eur J Endocrinol. 2002, 147:85-94. 10.1530/eje.0.1470085

7. Funahashi H, Imai T, Tanaka Y, et al.: Discrepancy between PNMT presence and relative lack of adrenaline production in extra-adrenal pheochromocytoma. J Surg Oncol. 1994, 57:196-200. 10.1002/jso.2930570312

8. Kimura N, Miura Y, Nagatsu I, Nagura H: Catecholamine synthesizing enzymes in 70 cases of functioning and non-functioning phaeochromocytoma and extra-adrenal paraganglioma. Virchows Arch A Pathol Anat Histopathol. 1992, 421:25-32. 10.1007/BF01607135

9. Eisenhofer G, Lenders JW, Goldstein DS, et al.: Pheochromocytoma catecholamine phenotypes and prediction of tumor size and location by use of plasma free metanephrines. Clin Chem. 2005, 51:735-44. 10.1373/clinchem.2004.045484

10. Ito Y, Fujimoto Y, Obara T: The role of epinephrine, norepinephrine, and dopamine in blood pressure disturbances in patients with pheochromocytoma. World J Surg. 1992, 16:759-63; discussion 763-4. 10.1007/BF02067379

11. Neumann HP, Bausch B, McWhinney SR, et al.: Germ-line mutations in nonsyndromic pheochromocytoma . N Engl J Med. 2002, 346:1459-66. 10.1056/NEJMoa020152

12. Eisenhofer G, Walther MM, Huynh TT, et al.: Pheochromocytomas in von Hippel-Lindau syndrome and multiple endocrine neoplasia type 2 display distinct biochemical and clinical phenotypes. J Clin Endocrinol Metab. 2001, 86:1999-2008. 10.1210/jcem.86.5.7496

13. Naranjo J, Dodd S, Martin YN: Perioperative management of pheochromocytoma . J Cardiothorac Vasc Anesth. 2017, 31:1427-39. 10.1053/j.jvca.2017.02.023

14. Gagner M, Lacroix A, Bolté E: Laparoscopic adrenalectomy in Cushing's syndrome and pheochromocytoma . N Engl J Med. 1992, 327:1033. 10.1056/NEJM199210013271417

15. Ludwig AD, Feig DI, Brandt ML, Hicks MJ, Fitch ME, Cass DL: Recent advances in the diagnosis and treatment of pheochromocytoma in children. Am J Surg. 2007, 194:792-6; discussion 796-7. 10.1016/j.amjsurg.2007.08.028 